\title{
Corrosion and Protection of Electronic Components in Different Environmental Conditions - An Overview
}

\author{
J. Starlet Vimala ${ }^{1}$, M. Natesan ${ }^{2}$ and Susai Rajendran ${ }^{*}, 3$ \\ ${ }^{1}$ Department of Chemistry, Sri Shakthi Institute of Engineering and Technology, Coimbatore-641062, Tamilnadu, India \\ ${ }^{2}$ Corrosion Protection Division, Central Electrochemical Research Institute, Karaikudi-630006, Tamilnadu, India \\ ${ }^{3}$ Corrosion Research Centre, Post Graduate and Research Department of Chemistry, GTN Arts College, \\ Dindigul-624005, Tamilnadu, India
}

\begin{abstract}
Corrosion of complex electronic equipment is an increasingly serious problem, causing expensive damage. Corrosion occurs through out the entire life cycle during different stages of manufacturing, assembly, transport and storage of components and assemblies and during field operations of the equipment. Presence of moisture, chloride, sulphur dioxide, hydrogen sulphide and other airborne corrosives, meteorological parameters etc influence the occurrence of corrosion. The present review describes the current understanding mechanism of corrosion of electronic components and equipments in different environmental conditions. The various corrosion testing methods and methods of corrosion prevention in these electronic devices have also been elaborated.
\end{abstract}

Keywords: Electronic devices, components, corrosion mechanism, corrosion control.

\section{INTRODUCTION}

There is an enormous increase in number and variety of applications of electronic equipment in commercial, industrial, and domestic environments. Corrosion is becoming an even more significant factor in the reliability of electrical and electronic equipments [1]. Literature survey has shown that the corrosion of electronic equipment is a serious problem, causing expensive damage which is estimated at $\$ 5$ billion in the United States alone for equipment repairs, downtime and replacements [2]. As electronics continue to shrink in size and grow in capacity, the importance of corrosion control increases [3]. Miniaturization of systems based on integrated circuits and small size components, close component spacing, separable electrical contacts having lower voltages and contact forces than before have resulted in failures of electronic equipments due to the formation of small quantities of corrosion products. Materials used in electronic equipment manufacture are used for their electrical or magnetic properties. Complexity, moisture, airborne corrosives, impressed currents, etc influence the occurrence of corrosion. Alloying them with chromium is not possible with these devices/equipments due to deleterious effects on the properties of interest. The failures of thin film circuits and printed circuit boards are divided into two classifications.

1. Dry electro migration occurring in the absence of moisture or electrolyte.

2. Simultaneous corrosion and electro deposition in the presence of moisture to yield electrolyte of reasonable conductivity.

*Address correspondence to this author at the Corrosion Research Centre, Post Graduate and Research Department of Chemistry, GTN Arts College, Dindigul-624005, Tamilnadu, India; E-mail: srmjoany@sify.com
With the increasing rate of corrosion in these microelectronic equipments/devices/components there is slow deterioration of electronics which poses great threat in future with unpredictable consequences.

In conclusion, a car can function even when pounds of metal are lost to corrosion but an electronic device fails with a minimum loss of 1 pico gram of the material.

\section{MATERIALS AND METHODOLOGY}

\section{Causes for Corrosion in Electronic Devices}

1) Service of devices such as Integrated Circuits in which metallic lines are often biased electrically relative to nearby lines.

2) Aggressive manufacturing processes.

3) Exposure to corrosive range of uncontrolled environments such as temperature, humidity and contamination.

4) Due to device miniaturization the width and separation of metal lines on integrated circuits(IC) devices have been cut in half approximately every 5 years and not less than 1 micron in the most advanced devices [4].

5) Reactive gaseous agents $-\mathrm{NO}_{\mathrm{X}}, \mathrm{SO}_{\mathrm{X}}, \mathrm{O}_{3}, \mathrm{H}_{2} \mathrm{O}_{2}, \mathrm{NH}_{3}$, $\mathrm{H}_{2} \mathrm{~S}$ plus volatile organic compounds.

6) Suspended inorganic and organic acids $\left(\mathrm{H}_{2} \mathrm{SO}_{4} \mathrm{HCl}\right.$, $\mathrm{HNO}_{3}$ ), suspended submicron hygroscopic ionic particles $\left(\mathrm{NH}_{4} \mathrm{HSO}_{4}, \mathrm{NH}_{3} \mathrm{NO}_{4},\left(\mathrm{NH}_{4}\right)_{2} \mathrm{SO}_{4}\right.$ plus others.

7) Other inorganic compounds and metals $-\mathrm{NaCl}, \mathrm{Fe}$, $\mathrm{Al}, \mathrm{Mg}, \mathrm{Ca}, \mathrm{K}$ suspended in the air. 


\section{Various Components in Electronic Devices and their Susceptibility to Corrosion}

\section{Integrated Circuits and Packages}

IC circuits are exposed to a number of aggressive media used in reactive ion etching (RIE) patterning of aluminium lines is got by wet etching or reactive ion etching which make the material prone to corrosion problems. RIE of aluminium metallization in plasmas containing combinations of aggressive gases such as chlorine, chloroform and boron tri chloride can lead to rapid corrosion during subsequent exposure to humid environment [5-8]. Other process solutions, like deionised water and organic solvents can become contaminated over time from dragged-in process chemicals and cause attack [9] Ionic contamination can arise from fluxes used during soldering processes, from handling and other materials such as dirt and dust. Standard test procedures have been developed to measure the level of contamination which essentially involves washing the whole Printed Circuit Board (PCB) in a solvent and measurement of ionic conductivity.

\section{Micro Pitting on Aluminium on Integrated Circuit}

Aluminium metallization, alloyed with copper form intermetallic $\mathrm{Al}_{2} \mathrm{Cu}$ compounds along the grain boundaries, which act as cathodic sites relative to the aluminium adjacent to the grain boundaries. This leads to dissolution of an aluminium matrix in the form of micro pitting during the rinsing step after chemical etching.

Corrosion of Aluminium by Chlorinated/Halogenated Solvents

Both liquid and vapour-phase halogenated solvents used for the production of Integrated Circuits and printed circuits readily corrode aluminium containing components. Water contamination of the solvents increases corrosion. Dilution of the stabilized solvents with aromatic or alcohol solvents leads to the breakdown of the halogenated solvents leading to the formation of chloride ions, which corrode aluminium and aluminium-copper alloys. Using $\mathrm{Al}-\mathrm{Cu}$ alloys, containing between 0.1 to 26 atom $\% \mathrm{Cu}$, deposited by magnetron sputtering and etching in sodium hydroxide solution, enrichments of copper have been developed selectively in the alloys. The enrichment of copper in the alloy beneath an alumina-based film free of copper species i.e. without requirement for oxidation of copper and incorporation of copper species in to the oxide was sufficient to generate increases in potential of similar magnitude to those found for specimens in which oxidation of copper had taken place. The potential increased by $-410 \mathrm{mV}$ with an increase in the level of enrichment to $-6.5 \mathrm{X} 1015 \mathrm{Cu}$ atoms $\mathrm{cm}^{-2}$ [10].

With the development of micro electronics, however, copper has now taken the place of Aluminium as the interconnection wire in VLSI due to the need for faster and more reliable interconnect schemes with shrinking critical dimensions of the VLSI technology. However in the presence of hydrogen sulphide and sulphur dioxide as pollutants (whose tolerable concentration for electronic equipment is 10 parts per billion and 30 parts per billion respectively [11].

Copper reacts with these pollutants and forms copper sulphide (dark greyish colour( and copper sulphate (greenish blue colour) Abbot [12] found that corrosion product formed on copper was mainly composed of copper oxide in less se- vere environments, while in more severe environments, a mixture of copper oxides and moderate amounts of copper sulphide have resulted.

Aluminium and Magnesium alloys are believed to play a role in improving the oxidation resistance of copper, although it is recently argued that magnesium fails to protect the surface from oxidation.

\section{Voltaic Corrosion in Integrated Circuit}

In Integrated Circuits, positively biased aluminium metallization is susceptible to corrosion. Combination of the electric fields, atmospheric moisture, and the contamination by halides leads to corrosion attack on any metals. Negatively biased aluminium metallization can also corrode in the presence of moisture due to high (basic) $\mathrm{pH}$ produced by the cathodic reaction of water reduction. High $\mathrm{pH}$ leads to dissolution of the passive surface layer of oxides and aluminium substrate with the corresponding increase in conductor resistance.

\section{Connectors and Contacts}

Low-force, low voltage separable connectors and contacts have wide use in the electronics industry. These contacts are copper coated with electroplated nickel and gold for improved corrosion resistance. Since, these coatings are thin and porous the contacts are to corrode as they retain water by capillary forces.

\section{Pore Creep in Electrical Contacts and Metallic Joints}

To prevent tarnishing of connectors and contacts, a noble metal (e.g. gold) is plated on the contact surface. However, defects in the protective coating can expose and corrode the substrate material at the imperfections. If the substrate is copper or silver and it is exposed to a sulphur or chloride containing environment, corrosion products can creep out from the pores and over the gold plating, forming a layer with high contact resistance.

Fretting Corrosion of Separable Connectors with Tin Finishes

Fretting corrosion in electronic components is the result of flaking of tin oxide from a mated surface on tin containing contacts. The problem becomes more frequent as tin is used to replace gold as a cheaper plating route. The only solution for this hard to diagnose often intermittent, problem is to replace the faulty part.

\section{Solder Corrosion}

Tin-lead alloys ranging between various compositions of lead and tin (either $\mathrm{Pb}$ rich or $\mathrm{Sn}$ rich) are most common solders used in electronic applications. Pure Sn forms protective oxide film while lead oxides formed are not stable and easily react with chlorides, borates and sulphates.Frankenthal and siliconolfi [13] found that both tin and lead rich $\mathrm{Pb}$ and Sn alloys form $\mathrm{SnO}$, most likely $\mathrm{SnO}$, during the initial exposure of oxide free surfaces to oxygen. When metallic tin becomes totally depleted from the surface lead is oxidized on the surface $\mathrm{Pb}-\mathrm{Sn}$ to yield mixed oxide. Lead forms unstable oxides which easily react with chlorides, borates, and sulphates. Contamination from assembly residues of low solids "no clean" fluxes is non-corrosive. Soldering is effectively carried out in a controlled atmosphere $\left(\mathrm{N}_{2}\right)$ containing a trace 
of less than $1 \%$ formic acid. This acid reacts with oxides on metals and metallized ions to form metal formates, which vaporize or decompose at soldering temperature evolving water vapour, hydrogen and carbon monoxide.

\section{Printed Circuit Board}

Printed circuit boards can suffer from variety of problems if the surface is contaminated with electrically conducting materials. When combined with moisture, contamination results in lowering of resistance between tracks and pads that can lead to corrosion of metals. It can also result in the formation of metal filaments, which grow between pads or tracks on rigid or flexible circuits and between oppositely charged metal terminations of components or between the pins of connectors. The essential conditions required for this are a combination of ionic contamination, moisture and an applied voltage. Equipment used under very dry conditions should not suffer from these problems. Unless there are large temperature fluctuations that result in condensation occurring on the surface of the circuitry or if the contaminants are hygroscopic and adsorb enough moisture to provide a liquid layer on the surface. At high relative humidity values less than $100 \% \mathrm{RH}$ a thin moisture layer will be present on the surface which is enough to decrease surface insulation resistance, cause corrosion or form metallic dendrites. The higher the humidity, the thicker is their moisture layer and faster the corrosion or dendrite growth. After copper electroplating, Water soluble copper salts, acid residues and plating additives if not removed from the panel can lead to ionic contamination of salts of tin and lead (during tin -lead plating), surfactants through urea and organic brighteners used if not removed by water rinse can be the cause for ionic contamination which is the source for corrosion. The unwanted copper foil removed by ammoniacal solution must also be removed in order to prevent the formation of ammonium complexes which will be formed during future fabrication process.

The peroxide solution used for stripping tin-lead to prepare bare copper boards is a strong oxidizer that can attack laminate as well as the metal.

\section{Hermetic Packages}

Hermetic packages constitute a small part of total micro electronic packaging and generally provide extra protection from the environment. Well, hermetic seals are sometimes fragile and can crack to create leaks as a result of handling or while joining to circuit boards.

Even devices in pin hole free hermetic packages can corrode $[14,15]$. Moisture adsorbed on the inner walls of the package can desorb and initiate failure. Devitrifying glass is one type of sealing material with a high moisture content that is evolved upon vitrifying [16].Moisture trapped inside a sealed cavity can leach ions from the sealing glass or other sources to form a conductive electrolyte. Once an ionic path exist between conductors, corrosion and failure by any mechanism as like integrated circuit failure mechanism can occur. Corrosion behaviour of plastic - encapsulated devices [17] have been found similar to unencapsulated devices. Nguyen and colleagues [18] used in insitu capacitance monitor to study moisture permeation in plastic packages [19].

\section{FACTORS INFLUENCING THE RATE OF CORRO- SION}

\section{Presence of Contaminants}

Ionic contamination on components occurs as a result of their manufacture or their handling. Handling residues during skin contact. Ionic residues from manufacture are as a result of incomplete cleaning after plating of the lead frames or wire leads. Non ionic contaminants may come from skin oils and hand creams.

\section{Contamination from Assembly}

Rosin is a well established soldering flux for electronics assembly. The activators in rosin fluxes are intended to enhance the ability of rosin to remove oxide films from metal surfaces, usually organic halide salts of organic acids under the influence of heat at soldering temperatures. These substances decompose, oxidize or form reactions soluble in either organic solvents or saponified water. These in the electronic assembly industry are known as white residues.

\section{Contamination from Handling and Storage}

\section{Handling}

Handling contamination is from finger oils, perspiration salts, flaking skin, hand cream and cosmetics, absorbed dusts and dirt, food particles, glove materials etc. Woven fabric

Gloves and other gloves used to handle these circuit boards and components must be washed or replaced repeatedly. Food drink and tobacco products must be prohibited in all storage, process and inspection areas.

\section{Water Vapour}

The plastic of the laminate material used for the circuit board and plastic used for component packages absorb and desorb moisture from the atmosphere as the local relative humidity rises and falls. The kinetics and thermodynamics of moisture diffusion in the plastic used in electronic assemblies are well understood and the effects are predicted accurately [20]. Problems caused by moisture uptake include delamination and measling of the circuit board as well as blow holing and solder blow holing and solder blow out in plated-through whole fillets.

\section{Presence of Airborne Contaminants}

This term applies to substances dissolved in moisture as well as to gaseous particulate species. Most common moisture borne contaminant is salt (sodium chloride) near the sea coast. Dust and air borne fibres and flakes in areas used for human activities. Gaseous contaminants common in industrial atmospheres such as hydrogen sulphide, sulphur dioxide and hydrogen chloride.

It has been reported [21] that, the following are the upper limits that are considered safe for electronics as compared with similar limits human exposures established in occupation safety health standards (given in Table 1).

\section{MECHANISM OF CORROSION}

\section{Electrolytic Corrosion}

This type of corrosion occurs when current passes through an electrolyte between two metallic electrodes as 


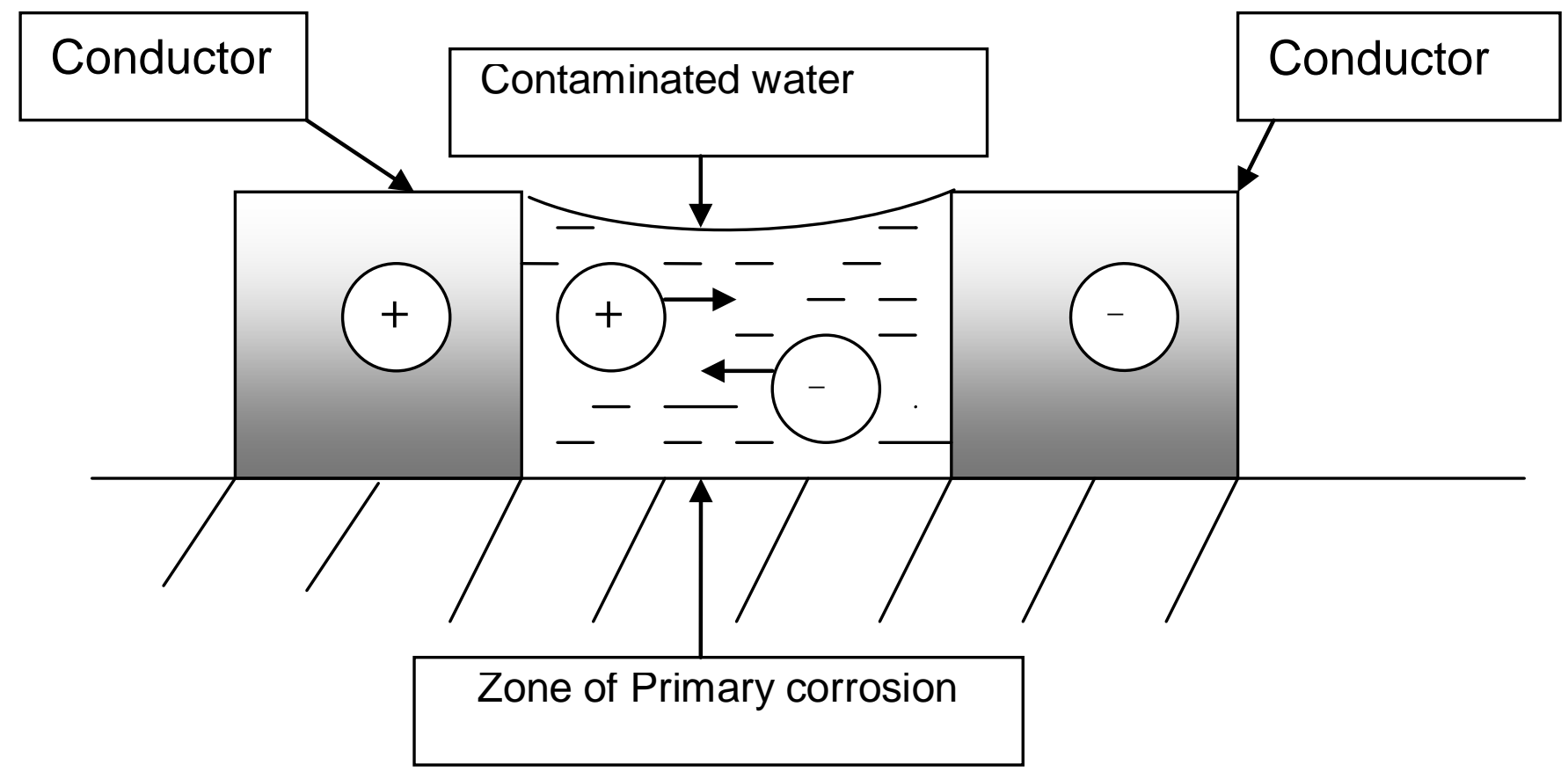

Fig. (1). Mechanism of electrolytic corrosion.

shown in the Fig. (1). In the presence of an electric field between adjacent conductors and a film of moisture because of an induced voltage between dissimilar metals.

Table 1. Airborne Contaminants

\begin{tabular}{|c|c|c|}
\hline Electronics & Corrodent & Human Exposure \\
\hline \hline $1-4 \mathrm{ppb}$ & $\mathrm{HCl}$ or $\mathrm{Cl}^{-}$ & $3000 \mathrm{ppb}$ \\
\hline $3-7 \mathrm{ppb}$ & $\mathrm{H}_{2} \mathrm{~S}$ & $14000 \mathrm{ppb}$ \\
\hline $1-70 \mathrm{ppb}$ & $\mathrm{SO}_{2}$ & $2000 \mathrm{ppb}$ \\
\hline
\end{tabular}

If two dissimilar metals in electrical contact are bridged by a drop of condensed moisture with a small quantity of ionic contamination present, a short circuited voltaic cell is formed and a current will flow as shown in Fig. (2). The voltage at such cell is equal to the difference between the electromotive forces (EMF) of component metals, the value of which, for some metals commonly used in printed circuit assemblies are given in the Table $\mathbf{2}$. The values of the voltages are referenced to hydrogen as zero.

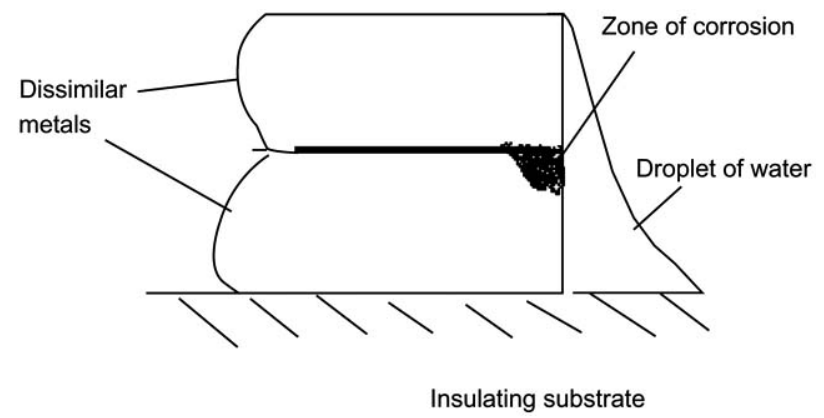

Fig. (2). Formation of voltaic cell.
Electrolytic corrosion can be avoided by removing all traces of moisture and ion contamination from the circuit and protecting it from recontamination. At times solder joints also fail due to stress corrosion.

\section{Electro Chemical Migration}

Electrolytic metal migration is a mechanism that affects microelectronic devices causing failure [22]. The failure due to dendritic growth bridging across adjacent conductors, due to metallic ions. Migration occurs between biased lands and under conditions conducive to electro- crystallization [23]. Conditions needed to form a dendrite are

1. The current density must reach high levels at the tip of the dendrite $\left(\mathrm{eg} .10^{3} \mathrm{~A} / \mathrm{cm}^{2}\right)$ achieved through spherical diffusion.

2. Sufficient liquid medium, (polar) such as condensed water, must be present in the migration path so that adequate ionic flux is developed to sustain the required dendritic growth rate [24, 25].

3. The applied voltage must exceed the sum of the anodic and cathodic potential in equilibrium with the electrolyte. Dendritic growths are observed with silver, copper, tin- lead, gold, gold-palladium conductors etc.,

\section{METHODS OF ANALYSIS OF CORROSION}

\section{i) Water Drop Migration to Analyze Dendrite Formation}

Evaporated silver, lead and copper land patterns on ceramic substrates are tested in water-drop experiment under 10 volt bias after being oxidized, sulphidized, and exposed to hydrochloric acid (dilute) solution to form metal chlorides. Five samples for each metal and surface condition are stressed. The reaction surface layers are less than or equal to 
Table 2. Electromotive Series of Common Metals (EMF at 298 K)

\begin{tabular}{|c|c|c|c|c|}
\hline Sl. No. & Symbol & Volts & Alloys & Volts \\
\hline \hline 1 & $\mathrm{Mg}$ & -2.37 & Brasses & -0.75 to +0.30 \\
\hline 2 & $\mathrm{Al}$ & -1.66 & Stainless steel & -0.30 to +0.10 \\
\hline 3 & $\mathrm{Zn}$ & -0.76 & Nickel- Iron & -0.45 to +0.30 \\
\hline 4 & $\mathrm{Fe}$ & -0.45 & Steels & -0.40 to +0.30 \\
\hline 5 & $\mathrm{Ni}$ & -0.26 & Bronzes \\
\hline 6 & $\mathrm{Sn}$ & -0.14 & \\
\hline 7 & $\mathrm{~Pb}$ & -0.13 & \\
\hline 8 & $\mathrm{Cu}$ & +0.34 & & \\
\hline 10 & $\mathrm{Ag}$ & +0.80 & & \\
\hline
\end{tabular}

$50 \mathrm{~nm}$ thick and discontinuous when viewed by electron microprobe. The oxide and sulphide layers either halt migration or reduce its occurrence. Dendrites are formed due to incomplete passivation. Metals chlorides being soluble in water accelerated metal migration. This study helps to understand whether a dendrite will grow or not in a given material following certain processes through which contamination occurs. No dendrites are obtained with water having PH 7. Acidic environments dissolve the oxide and promote metal migration.

As long as the metal is protected by insoluble layer of oxide, sulphide etc. metals are not able to migrate as the exchanging of ions and electrons across the anode and cathode interfaces cease, which is essential for oxidation and reduction process. A threshold voltage exists below which no dendrite grows. Dendrites produced at higher voltages are heavier and have ramiform structure while those at lower voltages are thinner and occur in fascicles aligned with the field.

\section{ii) Electrochemical Techniques}

1. Electrochemical impedance spectroscopy.

2. Chrono amperometry.

These are the two techniques available to appraise time failure for series of polymeric encapsulants that are formulated for the protection of micro electronic circuits. Pressure cooker test (PCT) conditions of $418 \mathrm{~K}$ and 2 atm steam (non-condensing) upto 290 Hours, elevated temperature ( $378 \mathrm{~K} / 100 \%$ relative humidity) and exposures to $3 \%$ aqueous $\mathrm{NaCl}$ are used to accelerate failure time. Electrochemical techniques are used extensively to determine the relationship between electrochemical processes and adhesion the DC and AC properties of polymer coatings and the thresholds for protection by organic coatings The use of accelerated corrosion tests is an important technology to characterize coatings for micro electronic devices. Chrono amperometry used as complementary technique with electro chemical impedance spectroscopy enhances prediction confidence for high performance coating materials.

Capacitance and impedance values are compared for coatings responses to accelerated conditions. Changes in material properties are detected in few hours under PCT conditions or few hundred hours at room temperature under selected conditions, silicone gel and elastomeric materials have smaller response than polyimides to water and ion exposures.

\section{iii) AC impedance Analysis of Residues on Printed Cir- cuit Boards}

Impedance techniques have been utilized to study raw materials for PCB assembly (e.g. solder paste) $[26,27]$ and to compare and elucidate conduction path ways in PCBs, by comparing surface conduction to bulk conduction processes both between adjacent plated through holes and between conductors on opposite sides of a PCB [28]. An equivalent circuit model is presented that assists in evaluating electrochemical parameters and the influence of environmental conditions and circuit line geometries on these parameters. The use of AC impedance methods offers several advantages for assessing risks associated with surface contaminants compared to usual dc methods. This measurement needs lesser time (minutes vs weeks) and the applied voltages are lesser \& hence will not induce dendritic growth during testing. The approach also facilitates modeling of the interfacial parameters which is useful as a predictive tool.

\section{iv) Cyclic Voltammetry and Potential Step Methods}

Failure of electronic devices by corrosion and dendrite formation in integrated \& thin film circuits and printed circuit boards are due to two reasons

1. Dry electro migration occurring in the absence of moisture or electrolyte [29].

2. Simultaneous corrosion and electro deposition in the presence of sufficient moisture to yield electrolyte of reasonable conductivity under accelerated corrosion conditions. $383 \mathrm{~K}, 85 \%$ relative humidity $(\mathrm{RH})$ and an imposed bias voltage dendrites, have been reported to grow from cathodically based films to anodically biased films resulting in short circuit [30-33].

Even noble metals such as gold and silver as well as copper, lead and tin [34] have been reported to be susceptible to such failures. The dendritic morphology and corrosion prevention of the metallization in various solutions are examined using a potential step testing method. In addition cyclic voltammetery is conducted on the metallized substrate and 
compared with that for pure metals to help identify particular electrochemical reaction occurring during the corrosion process. Cyclic Voltammetery is a useful electrochemical tool which is used to help identify the electrochemical reactions that occur on the metallization and compare these results with Cyclic Voltammeter performed on pure bulk materials.

\section{v) Submicron Dust Particle Exposure Chamber}

This chamber is designed to evaluate the environmental interactions on the reliability of electronics, the components of the environment include

\section{Corrosive gases got from fossil fuel combustion}

2. Coarse particles ( $>1$ Micron) formed by erosion of soil and minerals or flaking of biological materials.

3. Fine particles ( $<1$ micron) produced from corrosive gases through chemical and physical processes that occur in the atmosphere. The working volume of this chamber is $0.6 \mathrm{~m} \mathrm{X} 0.6 \mathrm{~m} \mathrm{X} 0.4 \mathrm{~m}$. Air that flows upwards over the boards at velocities up to $35 \mathrm{~m} / \mathrm{min}$, is continuously recirculated. Particles are introduced into the air immediately down stream from an ultra high efficiency particle filter and are then removed by the filter after one cycle through the system.

Tests of air velocities and particle concentrations show good uniformity over the entire cross section of chamber at the height at which circuits are tested over extended time periods. Testing of components and circuit boards are being initiated. This chamber (as shown in Fig. 3) has the following characteristics.

1. $0.01-1$ Micron particles $>$ or equal to $1 \mathrm{X} 10^{10} / \mathrm{Cubic}$ meter

2. Flow velocity - up to $35 \mathrm{~m} / \mathrm{min}$

3. Parallel airflow.

4. Uniform dust concentration.

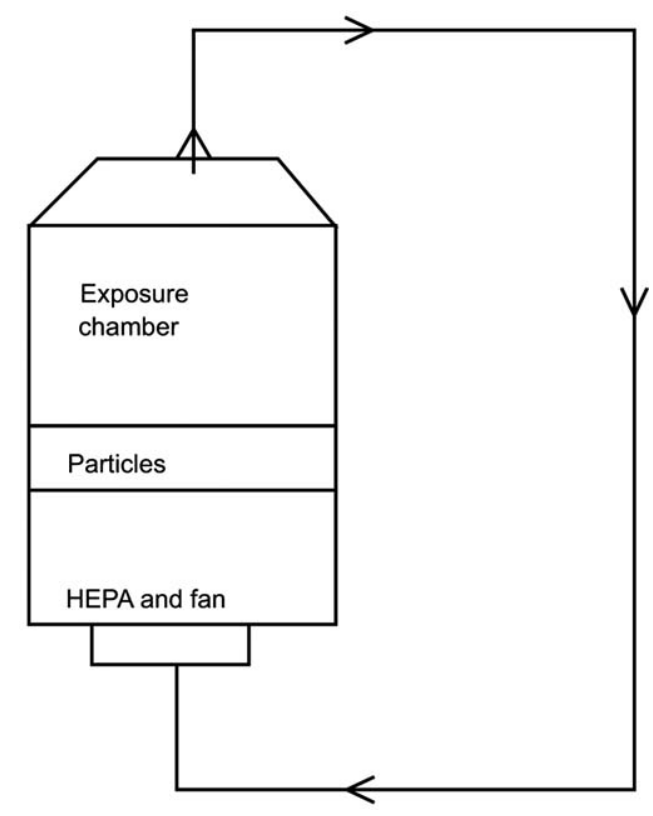

Fig. (3). Exposure chamber for life testing with sub-micron ionic dust particles.
The recirculating air flows upward through the HEPA (High Efficiency Particulate Arresting Filters). The particles are introduced into the air stream just above the HEPA filter and are removed from the system by the filter after one cycle. A screen (not shown) just above the HEPA filter ensures parallel airflow. Test vehicles are inserted in the upper part of the chamber.

\section{vi) Ion Chromatography to Determine Ionic Contamination}

The reliability of electronic materials depends on the cleanliness of the assemblies and has been extensively studied by several groups [35-37]. The reliability of these electronic equipments / devices are associated with electro chemical migration when the humidity and the contamination residues (from manufacturing process) are high. The contaminations are from fluxes used in soldering and hand sweat in handling of boards \& components.

The chloride from the activator substance in the flux and Sodium chloride from the hand sweat cause problems. Chloride forms readily complexes with metals and is corrosive. The analytical tool to determine the cleanliness is the extraction of contaminants from Printed Circuit Boards and measurement of the conductivity of the solute.

The conductivity is expressed as equivalents of Sodium Chloride in $\mu \mathrm{g} / \mathrm{cm}^{2}$, which gives the figure of Printed Circuit Board cleanliness. Sodium chloride is considered to be the worst contamination of all. So the total contamination is expressed as sodium chloride equivalents. The composition of ions contaminating the Printed Circuit Boards is determined quantitatively and qualitatively by ion chromatography. Analysis of the anions gives concentrations of halide ions and also weak organic acids used in some solder fluxes.

The ion chromatograph enables the analysis of the cleanliness of electronics. Analysis of both the cations and anions give the ionic pattern that pin point the contamination source [38]. The halide- alkali (HA) ratio gives a finger print of the contamination source. If this is high the halides come from hydrogen halides which are very reactive. The halides react with lead in the solder to form lead halide. If halide -alkali ratio is low, 1 or below; the halide source is alkali salts and halides are free to migrate. The migration damages are much worse.

\section{Vii) Corrosive Gas Test}

In this test corrosion behaviors and acceleration are investigated with respect to gas concentration, temperature, relative humidity, and wind velocity for various metals. Temperature of $338 \mathrm{~K}$, relative humidity of 80 to $85 \%$ and wind velocity of $0.2 \mathrm{~m} / \mathrm{s}$ are the appropriate test conditions. An exposure test of these various metals in different environments like industrial, urban and suburban areas is also studied. The effect of $\mathrm{SO}_{2}$ and the corrosion rate. So also a mixture of $\mathrm{SO}_{2}$ and $\mathrm{NO}_{2}$, their effects on these metals are studied. The amounts of corrosion of these metals are deduced from acceleration.

Acceleration $=$ Weight loss by gas test $-\left[\mathrm{mg} / 100 \mathrm{~cm}^{2} /\right.$ day $]$

$$
\text { Weight loss by exposure test - }\left[\mathrm{mg} / 100 \mathrm{~cm}^{2} / \text { day }\right]
$$

From these tests the most appropriate metal to be used in electric and electronic components can be arrived at. How- 
ever it is necessary to set the test conditions for acceleration in sufficient consideration of the operating environment.

\section{Viii) FIELD and Laboratory Corrosion Methods for Contact Materials: (Gold and Tin Plated)}

The difference in contact resistance between $0.5 \mu \mathrm{m}$. tin and gold platting after 10 days of exposure in air at different relative humidity with various pollutants or combination of pollutants added are studied. The contact resistance increases with relative humidity due to increase in corrosion rate. The importance of relative humidity to accelerate the atmospheric corrosion of metals such as iron, Cobalt, Nickel and copper is well established Samples are exposed under indoor conditions and measurement of pollutant concentrations are performed on a weekly basis. Corrosion products formed during field or laboratory exposures are investigated by X-ray photo electron spectroscopy (XPS) contact resistance measurements, in few cases by scanning electron microscopy (SEM). XPS measurements are made with a Leybold Heraeus ESCA /Auger spectrometer LH. 2000 fitted with an aluminium anode and spherical analyzer. XPS yields information on elemental composition and chemical state of the uppermost 1-5 $\mathrm{nm}$ of the investigated sample surface. For the field study $\mathrm{Au}$ and $\mathrm{Sn}$ electroplated samples after a year of exposure at various outdoor environments are studied.

\section{ix) Determination of Hermicity of Electron Devices by Dye Penetration}

i. In these methods, a penetrant dye solution is applied locally to an area of the component to be tested for leaks, or the entire component is immersed in a bath of the penetrant. After contact with the penetrant dye for a specified time, the device is cleaned and visually inspected for dye penetration.

ii. Method A, Penetrant Capillary: The penetrant dye is applied locally, or the device is immersed in a bath of the dye. This method, in which no external pressure is exerted to force the penetrant dye through the leak, is particularly suited to components and sub assemblies without an internal cavity or to sub assemblies that cannot be totally reimbursed.

iii. Method B, Penetrant pressure-the component, with an internal cavity is immersed in a bath of the penetrant dye, the bath is pressurized to force the dye solution through any leaks that may exist.

iv. Method C, penetrant-pressure followed by vacuum The Component, with an internal cavity is immersed in a bath of the penetrant dye, which may not be pressurized.

\section{VOLATILE CORROSION INHIBITOR MECHANISM}

The mechanism of protection provided by volatile corrosion inhibitors has been studied mostly on ferrous based metals. It is not precisely known what exactly the mechanism of protection is, but it is believed that the monomolecular inhibitor coating that condenses from the vapour phase on the ferrous metal surfaces is dissolved by moisture to create the ions necessary for protection. The weakly adsorbed inhibitor ions passivate the surfaces by saturating the metal gas interface and by polarization of the metal. The passivation mechanism on non ferrous metals has not been as extensively studied. Tolytriazole is believed to interact with the cuprous oxide film normally present on copper surfaces, forming a protective polymeric triazole film.

It has been further suggested that certain amine salt vapours also interact with cuprous oxides to form organo metallic compounds which may play an important part in the overall protective mechanism [39].

The use of these types of inhibitors coupled with steps that industry has taken to reduce corrosion of electronic assemblies will further reduce this industry wide problem.

\section{RESULTS, DISCUSSION AND CONCLUSION}

\section{Corrosion Control}

Steps taken to eliminate corrosion problems including hermetic sealing of components in cavities, use of protective coatings, encapsulation, use of noble metal platting, increased use of more corrosion resistant metal alloys and the use of moisture absorbing desiccants have all served to reduce, but not eliminate corrosion in electronic components [40].

Volatile corrosion inhibitors (VCIs) can provide an effective means of protecting electronic components from corrosion. These compounds have sufficient vapour pressures $\left(10^{-3}\right.$ to $10^{-5} \mathrm{~mm} \mathrm{Hg}$ at $\left.70^{\circ} \mathrm{F}\right)$ to allow vaporization and subsequent condensation and adsorption on metal surfaces as a mono-molecular passivating layer. The ultra-thin protective layer does not interfere with conductivity or resistivity of the base metal. This direct method of corrosion protection by means of metal passivation in many cases is superior to traditional indirect methods of corrosion protection such as the use of drying agents and the protective coatings.

The volatile corrosion inhibitors are DICHAN (dicyclohexylammonium nitrite), tolytriazole and a proprietary mixed amine salt compound. DICHAN has been used extensively for the protection of mostly ferrous based metals. Tolytriazole has been widely used in protecting copper alloys as a surface treatment and in the vapour phase. This is the most widely used inhibitor in electronics industry till date.

Other group of inhibitors based on salts of aliphatic amines or alkaholamines and carboxylic acids are also gaining favour as multi-metal inhibitiors. Mixtures of different amine salts to optimize vapour pressures of the mixture and inhibitive properties toward a wider variety of metals appear to offer potential as an inhibitor for multi-metal electronic systems.

Corrosion protection of electronic equipment requires unique solutions complexity, moisture, airborne corrosives, "impressed currents", etc., influence the occurrence of corrosion. Introduction of micro computers has warranted development of new methods of corrosion protection for equipment exposed to outdoor or polluted environments. On exposure to condensing humidity and hydrogen sulphide, triazole, cyclic amine nitrate salts, and cyclic amine salts provides significant level of protection. Cyclic amine fatty acid salts and alcohol - amine salts enhance the corrosion of electronic components. Thus these components are proved ineffective. The number of options available to the electronic designer to minimize corrosion is indeed limited due to specific material and space limitations. Therefore controlling the environment 
becomes an important option, which when properly implemented significantly extends the service life of the equipment.

Vapour phase inhibitors represent a method of chemically "conditioning "the environment that consequently become less corrosive to the metals. Mixed inhibitors are best suited for the requirements of electronic industry. Corrosion in electronic equipment is often simulated by the design, and thus the compounds capable of inhibiting both cathodic and anodic reactions have optimum effectiveness.

\section{Mechanism of Vapour Phase Inhibitors}

Vapour phase inhibitors perform by continuously depositing a mono molecular protective film, which is physically adsorbed on the metal surface. In the absence of polar electrolyte, desorption takes place causing the inhibitor molecules to recombine, leaving the substrate essentially free of trace organic deposits. Due to monomolecular nature of protective films, the possibility of changing even most sensitive surface properties, conductivity and capacitance is virtually eliminated for all practical purposes. Corrosion inhibitors capable of producing chemisorbed layers should be avoided from use on electronic contact surfaces, as they can produce irreversible effects which may result in contact resistant changes.

A selected class of organic corrosion inhibitor studied to determine the effectiveness on electronic substrates offers conclusions as below.

1. Cyclic amine carboxylated fatty acids attacked bolts, Solder and jumpers.

2. Alcoholic amine carboxylate enhance corrosion of diodes.

3. Triazoles provide protection to bolts and solder.

4. Cyclic amine carboxylated nitrate protects components under high humidity conditions.

5. Cyclic amine carboxylates protect circuit board components in presence of hydrogen sulphide.

Thus by proper evaluation of inhibitor systems, proper protection of electronic components can be had.

Effect of $\mathrm{Mg}$ alloying in $\mathrm{Cu}$ with pretreatments on corrosion behavior of $\mathrm{Cu}$ was studied, which was compared with that of a $\mathrm{Cu} \mathrm{Al}$ alloy. It was found that, at $673 \mathrm{~K}$ under oxygen pressure of $0.1 \mathrm{MPa}$, although the corrosion resistance of $\mathrm{Cu} \mathrm{Mg}$ alloy was evidently improved in comparison with that of pure $\mathrm{Cu}$, it was worse than that of $\mathrm{Cu} A$ alloy. Three possible reasons were i) $\mathrm{C}$ atoms were incorporated into the $\mathrm{MgO}$ surface layer, ii) Fissures were produced in $\mathrm{MgO}$ layer, iii) The adherence of $\mathrm{MgO}$ surface layer on $\mathrm{Cu}$ was poor. The first one could be due to formation of a new intermetallic phase of $\mathrm{MgCu}_{2}$ on the surface of $\mathrm{Cu}$ sample during the formation of $\mathrm{MgO}$ surface layers, while the latter two were attributed to low Pilling - Bedworth ratio of $\mathrm{MgO}$ system smaller than 1 .

\section{REFERENCES}

[1] Gutten JD. Corrosion in electronic industry. Corrosion 1987; 13: 1107-12

[2] Miksic BA, Martin PJ. Proceedings of $6^{\text {th }}$ European Symposium on Corrosion Inhibitors; Ferrara, Italy; 1985; pp. 941-950.
[3] Miksic BA, Vignetti A. Vapour Corrosion Inhibitors: successful field applications in electronics. NACE Corrosion Conference; March 2000; Orlando; Paper \# 7, 2000.

[4] Lee WY, Eldridge JM, Schwartz GC. Reactive ion ethching induced corrosion of Al and Al-Cu films. J Appl Phys 1981; 52: 2994.

[5] Hoge CE. Corrosion criteria for electronic packaging II. Calculated corrosion currents and acceleration factors components, hybrids manufacturing technology. IEEE Trans 1990; 13: 1098-104.

[6] Eldridge JM. $3^{\text {rd }}$ Conference on Electronic Packaging, Materials and Processing in Micro Electronics (M.E. Nicholson, Ed), ASM Metals park, OH 1987; p. 283

[7] Maa JS, Gossenberger H, Paff RJ. Effect of post-etch treatment on chlorine concentration of AlSi and ti-capped AlSi films. J Vac Sci Technol 1990; B8(5): 1052-7.

[8] Brusic VA, Frankel GS, Plechaty CK, Rush BM. Corrosion study of an Al-Cu alloy exposed to reactive ion etching. Corrosion 1991; 47: 35 .

[9] Thomas ME. Spin-on stacked films for low-k eff dielectrics. IEEE Trans Comp Hybrids Manuf Technol 1984 ; 4 ; 245-52.

[10] Garcia SV, Colin F, Skeldon P, Thompson GE, Bailey P, Noakes TCO, Habazaki H, Shimizu K. Effect of copper enrichment on the electrochemical potential of binary $\mathrm{Al}-\mathrm{Cu}$ alloys. J Electrochem Soc 2007; 151(1): B16-B21.

[11] Leygraf C, Zakipour S, Henriksen J, Avillien P, Wagner M. Proceedings of $10^{\text {th }}$ Scandinavian Corrosion Cong; Swedish Corrosion Institute: Stockholm 1986; Vol. 4: p. 19.

[12] Abbott WH. Proceedings Holm seminar on Electric Contact Phenomena; Illinoi's Institute of Technology: Chicago, IL 1973; 94.

[13] Frankenthal RP, Siconolfi DJ. An AES study of the oxidation of a $97 \mathrm{~Pb}-3 \mathrm{Sn}$ alloy. Corros Sci 1981; 21: 479-86.

[14] Swartz WE, Linn JH, Ammons JM, Kovac M, Wilson K. The adsorption of water on metallic packages. Proc $21^{\text {st }}$ Ann Reliability Phys 1983; 21-52.

[15] Pecht M. A model for moisture induced corrosion failures in micro electronic packages. IEEE Trans Comp Hybrids Manuf Technol 1990; 13: 383-9.

[16] Lowry RK, Van Leeuwen CJ, Kennimer BL, Miller LA. A reliable dry ceramic dual-in-line package. Proceedings of the $16^{\text {th }}$ Annual Reliability Physics Symposium, Institute of Electrical and Electronic Symposium: New Jersey 1978; 16: p. 207.

[17] Peterson PW. The performance of plastic encapsulated CMOS microcircuits in a humid environment. . IEEE Trans Comp Hybrids Manuf Technol 1979; 2: 340-65.

[18] Nguyen T, Kovac CA. Moisture diffusion in electronic packages, SAMPE Electronic Materials \& Processes Conference, June 1987; pp 574-89.

[19] Tummala RR, Rymaszewski EJ. Microelectronics Packaging Handbook. Van Nostrand Reinhold, New York 1989.

[20] Turnbull RB, Flux SA. A new flux choice for automatic machine soldering. Proceedings Internepcon; Brighton, UK 1982; pp. 214-8.

[21] Rice D, Kral J. Quintech'85, paper 90. ASM/NACE, San Francisco, California 1985

[22] Lea C, Howie FH, Seah MP. Blow holing in PTH solder fillets. The Scientific frame work leading to recommendations for its elimination circuit world, 1987; Vol. 13, No. 3: pp. 11-20.

[23] Giacomo Di. Metal migration ( $\mathrm{Ag}, \mathrm{Cu}, \mathrm{Pb})$ in encapsulated modules and time-to-fail model as a function of the environment and package properties. Proc Reliability Phys Symp 1982.

[24] Brous J. Electrochemical migration and flux residues-causes, and detection. Proc Tech Program NEPCON West 1992; 1: 386-93.

[25] Barton JL, Bockris JO'M. The electrolytic growth of dendrites from ionic solutions. Proc R Soc London Ser A 1962; vol. 268: pp. 485-505.

[26] Granata RD, Tiedge KW. Electrochemical evaluation of conformal coatings used in electronic applications, Proceedings of Corrosion; Nashville, TN 1992; Paper No. 469.

[27] Sinclair JD. Interaction of the environment with indoor metallic surfaces. J Electrochem Soc 1998; 135: 89C-95C.

[28] Raleigh C, Prack E. Dielectric studies of solder paste fluxes and application to no-clean paste formulations. Proceedings of the IEMT Symposium, IEEE/CHMT; USA 1989; 307.

[29] Polczynski M, Seitz M, Hirthe R. A new technique for monitoring solder paste characteristics for statistical process control. Surf Mount Technol 1990; 54. 
[30] Frankenthal RP, Siconolfi DJ, Sinclair JD. Proceedings of the second international symposium on corrosion and reliability of electronic materials and devices; The Electrochemical Society, Pennington; 1981; 93: pp. 357-63.

[31] Dumoulin P, Seurin JP, Marce P. IEEE Transaction on components, Hybrids and Manufacturing Technology. Institute of Electrical and Electronics Engineers; NewYork 1982; 5: p. 479.

[32] Sbar N. Proc Conf IEEE Electronic components. Institute of Electrical and Electronics Engineers New York 1976; 277.

[33] Leidheiser H Jr, Mills DJ, Bilder W. Fall meeting of the electrochemical society, Inc., 1986. In: Kendig M W, Leidheiser H Jr, Eds. Proceedings of the Symposium on Corrosion Protection by Organic Coatings; The Electorchemical Scoiety, San Diego; 1987; 87: pp. 23-36.

[34] Leidheiser H, Granata RD. IBM. J Res Dev 1988; 32(5): 582-90.
[35] Frankenthal RP, Becker WH. Corrosion failure mechanisms for gold. Metallizations in electronic circuits. J Electrochem soc 1979; 126: $1718-25$.

[36] Leidheiser H, Granata RD. IBM. J Res Dev 1988; 32(5): 582-90.

[37] Bockris JO’M, Reddy AKN. Modern Electrochemistry. Plenum press: NewYork 1970; vol. 1 and 2.

[38] Sinclair JD. An instrumental gravimetric method for indexing materials, contaminants, corrosion products according to their hygroscopicity. J Electrochem soc 1978; 125: 734-42.

[39] Sard R, Leidheiser H, Ogburn F, Eds. Properties of electrodeposits; their measurement and significance. Electrochemical Society: Pennington, New Jersey 1975; 74: p. 142.

[40] Gagne JJP. Proc conf IEEE electronic components, institute of electrical and electronics engineers, New York, 1982; p.214.

(C) Vimala et al.; Licensee Bentham Open.

This is an open access article licensed under the terms of the Creative Commons Attribution Non-Commercial License (http://creativecommons.org/licenses/by$\mathrm{nc} / 3.0 /$ ) which permits unrestricted, non-commercial use, distribution and reproduction in any medium, provided the work is properly cited. 